Wright, M. F., Haddon, L., \& Smahel, D. (2015). Editorial: The mediation of children's digital technology usage. Cyberpsychology: Journal of Psychosocial Research on Cyberspace, 9(1), article 1. doi:

10.5817/CP2015-1-1

\title{
Editorial: The mediation of children's digital technology usage
}

\author{
Michelle F. Wright ${ }^{1}$, Leslie Haddon², David Smahel ${ }^{3}$ \\ 1,3 Masaryk University, Brno, The Czech Republic \\ ${ }^{2}$ Department of Media and Communications, London School of Economics, UK
}

Dear researchers, colleagues, and readers interested in research on cyberspace,

We are pleased to present a special issue for Cyberpsychology: Journal of Psychosocial Research on Cyberspace. The aim of the special issue is to build upon existing knowledge concerning the mediation of children's use of digital technology. We sent out the call for abstracts in the Fall of 2014, with the goal of receiving submissions on the role of family members, peers, and teachers in mediating children's digital technology usage. Another goal was to receive submissions employing either child-centered, parentcentered, and teacher-centered approaches, or those utilizing cross-cultural perspectives. Therefore, we titled the special issue, "The Mediation of Children's Digital Technology Usage," a title we thought captured a broad approach to this topic.

Six papers were included in this special issue. The topics are diverse, bringing together research on children's evaluations of parental mediation, parents' perspectives of their technology mediation, gendered-based parental mediation, peer mediation, teachers' mediation, and cross-cultural differences in technology mediation by parents, friends, and teachers. The articles in our special issue represent research from three continents - Europe, Asia, and North America - and include participants from Belgium, China, the Czech Republic, Greece, Estonia, Italy, Latvia, Malta, the Netherlands, Portugal, Romania, Spain, the United Kingdom, and the United States. These studies also include both qualitative and quantitative research designs. We employed the terminology of "children" in this editorial to describe the mediation of both children's and adolescents' digital technology usage. This terminology was also adopted because the ages of children in the special issue range from 0 to 16 years.

In this special issue, Haddon emphasized children's perspectives on their parents' mediation of their internet usage, which is an understudied area in the mediation literature. His findings revealed that children are generally positive about parental mediation but they are skeptical of such mediation, believing it sometimes lacks credibility. Age-related differences were also acknowledged, and Haddon proposed that younger children and older children have different developmental needs, which impact their evaluations of parental mediation. This study is important as it provides valuable information for the literature on children's perceptions regarding parental mediation.

Nikken and de Haan took a different approach to studying parental mediation by focusing on parents' perspectives instead of the child-centered approach employed by Haddon. Another unique characteristic of this study is that parents reflected on their mediation of younger children's ( 0 to 7 years old) digital technology usage. The researchers appeal for more technology training for parents as parents with fewer technology competencies had children who were more active on social media.

Utilizing a similar approach as Nikken and de Haan, Talves and Kalmus also investigated parents' perspectives of their children's digital technology usage. Their concerns were on whether parents' mediational approaches varied based on the gender of their children. Interestingly, their findings revealed that this relationship is more complex, arguing that researchers should consider gender-based mediational 
strategies and the impact of parent-child interactions and parents' socio-demographic characteristics on these strategies.

Moving away from parental mediation, Mascheroni, Vincent, and Jimenez examined peer mediation of children's digital technology usage. They argued that mobile communication and social networking sites allow constant access to peer culture, and that this peer culture impacts the photos that children share online. Their findings indicate that there are sexual double standards in peer norms concerning the posting of photos online.

Karaseva, Siibak, and Pruulmann-Vengerfeldt investigated teachers' mediation of children's use of digital technology. Teachers primarily acted as guides to help children navigate the opportunities that digital technology provide. In addition, teachers' mediational strategies varied based on their pedagogical beliefs and subject domains. Findings from this research have implications for improving teacher training.

The last article presents a study conducted by Wright, focusing on cross-cultural differences in the mediation of children's technology usage. The aim of study was to compare the roles of different mitigating agents (i.e., parents, teachers, friends) in buffering the negative effects associated with cyber victimization among Chinese and American children. Findings from this study suggest that culture and various mitigating agents have different impacts on children's cyber victimization and their psychosocial adjustment difficulties.

We hope that you will enjoy reading the papers in the special issue, and that you will find the ideas useful for aiding future research. Furthermore, the findings generated from these papers can be useful for the development of policy and intervention strategies concerning the mediation of children's digital technology usage. We want to take all the contributors, authors, and reviewers who made this special issue possible.

Michelle F. Wright, Leslie Haddon, \& David Smahel

\section{Issue Content}

Article 1:

Editorial: The mediation of children's digital technology usage

Michelle F. Wright, Leslie Haddon and David Smahel

doi: $10.5817 /$ CP2015-1-1

Article 2:

Children's critical evaluation of parental mediation

Leslie Haddon

doi: $10.5817 / C P 2015-1-2$

Article 3:

Guiding young children's internet use at home: Problems that parents experience in their parental mediation and the need for parenting support

Peter Nikken and Jos de Haan

doi: $10.5817 /$ CP2015-1-3

Article 4:

Gendered mediation of children's internet use: A keyhole for looking into changing socialization practices

Kairi Talves and Veronika Kalmus

doi: $10.5817 / C P 2015-1-4$

Article 5:

"Girls are addicted to likes so they post semi-naked selfies": Peer mediation, normativity and the construction of identity online

Giovanna Mascheroni, Jane Vincent and Estefanía Jimenez

doi: $10.5817 /$ CP2015-1-5

Article 6:

Relationships between teachers` pedagogical beliefs, subject cultures, and mediation practices of students' use of digital technology 
Article 7:

Cyber victimization and adjustment difficulties: The mediation of Chinese and American adolescents' digital technology usage

Michelle F. Wright

doi: $10.5817 /$ CP2015-1-7

\section{About Journal}

The 'Cyberpsychology: Journal of Psychosocial Research on Cyberspace' is a web-based, peer-reviewed scholarly journal. The first peer-reviewed issue was published in September 2007. The journal is focussed on social science research about cyberspace. It brings psychosocial reflections of the impact of the Internet on people and society. The journal is interdisciplinary, publishing works written by scholars of psychology, media studies, sociology, political science, nursing, and also other disciplines. The journal accepts original research articles, as well as theoretical studies and research meta-analyses. Proposals for special issues are also welcomed.

The journal is indexed with EBSCO Academic Search Complete, the Directory of Open Access Journals, SCOPUS and the Czech Database of Scientific Journals.

\section{Editor}

Prof. David Smahel, M.Sc. et Ph.D., Faculty of Social Studies, Masaryk University, Czech Republic E-mail: smahel(at)fss.muni.cz

\section{Associate Editor}

Prof. Kristian Daneback, Ph.D., University of Gothenburg, Sweden

E-mail: kristian.daneback(at)socwork.gu.se

\section{Guest Editors of Special Issue "The Mediation of Children's Digital Technology Usage"}

Michelle F. Wright, Masaryk University, Brno, Czech Republic

Email: michelle.wright(at)mail.muni.cz

Leslie Haddon, London School of Economics, UK

Email: LeHaddon(at)aol.com

David Smahel, Masaryk University, Brno, Czech Republic

E-mail: smahel(at)fss.muni.cz

\section{Editor Assistant}

Lenka Dedkova, M.A., Faculty of Social Studies, Masaryk University, Czech Republic

E-mail: Idedkova(at)fss.muni.cz

\section{Editorial Board:}

Prof. Kaveri Subrahmanyam, Ph.D., California State University, Los Angeles, USA

Prof. Herbert Hrachovec, Ph.D., University of Vienna, Austria

Prof. Dr. Micheline Frenette, Universite de Montreal, Canada

Prof. Alexander E. Voiskounsky, Ph.D., Lomonosov Moscow State University, Russia

Prof. Michael W. Ross, Ph.D., DrMedSc, MPH, MPHEd, University of Texas, Houston, USA

Prof. Petr Macek, CSc., Masaryk University, Czech Republic

Prof. Olle Findahl, World Internet Institute, Sweden 
Prof. Jochen Peter, Ph.D., University of Amsterdam, Netherlands

Prof. Veronika Kalmus, Ph.D., University of Tartu, Estonia

Prof. Joshua Fogel, Ph.D., Brooklyn College of the City University of New York, USA

Prof. Gustavo S. Mesch, Ph.D., University of Haifa, Israel

Michelle Wright, Ph.D., Masaryk University, Czech Republic

Václav Štětka, Ph.D., Charles University, Czech Republic

Andra Siibak, Ph.D., University of Tartu, Estonia

Adjunct Prof. Birgit U. Stetina, Ph.D., University of Vienna, Austria

Lukas Blinka, Ph.D., Masaryk University, Czech Republic

\section{Advisory Board:}

Prof. Bente Traen, Ph.D., University of Oslo, Norway

Prof. Charles Ess, Ph.D., University of Oslo, Norway

Prof. Dr. Ilse Kryspin-Exner, University of Vienna, Austria

Prof. PhDr. Jan Jirák, Ph.D., Charles University, Czech Republic

Prof. Vasja Vehovar, Ph.D., University of Ljubljana, Slovenia

Prof. Larry D. Rosen, Ph.D., California State University, USA

Prof. Patricia M. Greenfield, Ph.D., University of California, USA

Prof. Peter K Smith, University of London, England

Prof. Nicola Döring, IImenau University of Technology, Germany

Prof. Kimberly Young, Ph.D., St. Bonaventure University, USA

Prof. Jos de Haan, Ph.D., Erasmus University, Netherlands

Prof. Zbyněk Vybíral, Ph.D, Masaryk University, Czech Republic

Prof. Monica Whitty, Ph.D., University of Leicester, UK

Prof. Alistair Duff, Ph.D., Edinburgh Napier University, Scotland

Assoc. Prof. Alfred Choi, Ph.D., Nanyang Technological University, Singapore

Prof. Thurasamy Ramayah, Universiti Sains Malaysia, Malaysia

Assoc. Prof. Neil Coulson, Ph.D., The University of Nottingham, UK

Assoc. Prof. Kenneth C. C. Yang, Ph.D., University of Texas at El Paso, USA

Assoc. Prof. Sun Sun Lim, Ph.D., National University of Singapore, Singapore

Prof. Sameer Hinduja, Ph.D., Florida Atlantic University, USA

Assoc. Prof. Jana Horáková, Ph.D., Masaryk University, Czech Republic

Assoc. Prof. Radim Polčák, Ph.D., Masaryk University, Czech Republic

Assoc. Prof. Pille Pruulmann-Vengerfeldt, Ph.D., University of Tartu, Estonia

Assist. Prof. Alexander Schouten, Ph.D., Tilburg University, Netherlands

Assist. Prof. Ewa S. Callahan, Ph.D., Quinnipiac University, USA

Assist. Prof. Regina van den Eijnden, Ph.D., Utrecht University, Netherlands

PhDr. Ing. Petr Soukup, Charles University, Czech Republic

Janis Wolak, Ph.D., University of New Hampshire, USA

Francesca Romana Seganti, Ph.D., Sapienza University of Rome, Italy

Jeff Gavin, Ph.D., University of Bath, UK

Hana Macháčková, Ph.D., Masaryk University, Czech Republic

Michael Fenichel, Ph.D., New York, USA

Leslie Haddon, Ph.D., London School of Economics, UK

Monica Barbovschi, Ph.D., Masaryk University, Czech Republic

Jan Širůček, Ph.D., Masaryk University, Czech Republic

\section{Publisher}

Masaryk University, Faculty of Social Studies

Jostova 10, 60200 Brno

Czech Republic

\section{Publication Schedule}

Twice per year (July and December) plus special issues 


\begin{abstract}
About author(s)
Michelle F. Wright is a postdoctoral research fellow at Masaryk University in the Czech Republic. Her major research interests include the contextual influences, particularly cultural and familial, on adolescents' social behaviors, and their pursuit and achievement of peer status. For the past several years, she has studied victimization and aggression through electronic technologies among children, adolescents, and young adults.
\end{abstract}
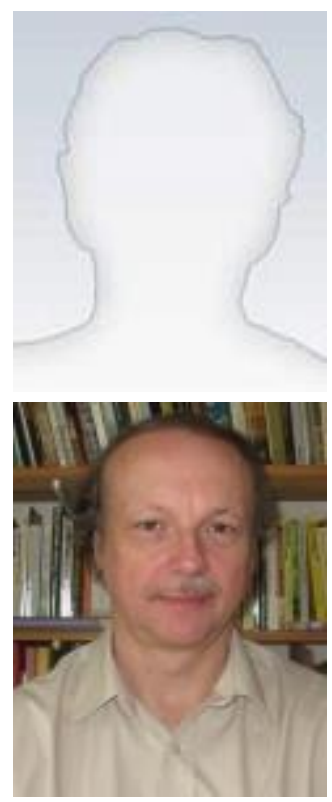

Dr Leslie Haddon is a visiting lecturer in the Department of Media and Communications, London School of Economics. His research over the past decades has in general focused on the social shaping and consumption of ICTs. From 20062014 he had been part of the coordinating team of the EU Kids Online project that examined online risks and children and he also participated in the Net Children Go Mobile project on children's use of smartphones and tablets.

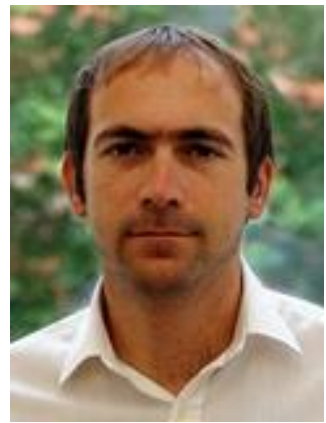

David Smahel, Ph.D. is the Professor at the Institute of Children, Youth and Family Research, Masaryk University, the Czech Republic. He directs the workgroup "Cyberpsychology" (http://www.cyberpsychology.eu/team) which researches socialpsychological implications of the internet and technology. Current research focuses on adolescents' and adults' internet use, the online risks of children and adolescents, the construction of online identities and virtual relationships, and online addictive behavior. He is editor of Cyberpsychology: Journal of Psychosocial Research on Cyberspace and has co-authored book Digital Youth: The Role of Media in Development (Springer, 2011). Smahel also published in several international journals such as Developmental Psychology, Cyberpsychology \& Behavior, Zeitschrift für Psychologie, European Journal of Developmental Psychology and others. He is also author of several book chapters, such as in Encyclopedia of Cyber Behavior, Encyclopedia of Adolescence, Internet Addiction: A Handbook and Guide to Evaluation and Treatment, Gesundheit und Neue Medien etc. 